\title{
FACTORES DE VULNERABILIDAD COGNITIVA DE LA PERMANENCIA EN CALLE: DESESPERANZA Y DERELICCIÓN*
}

\author{
COGNITIVE VULNERABILITY FACTORS OF STAYING ON THE STREET: \\ HOPELESSNESS AND DERELICTION
}

\author{
Juan David Zabala-Sandoval ${ }^{* *}$ \\ https://orcid.org/0000-0001-8999-4053 \\ Universidad de Chile \\ Santiago-Chile \\ Universidad de Ibagué \\ Ibagué-Colombia \\ María Paulina López-Parra \\ https://orcid.org/0000-0002-9174-806X \\ Universidad de Ibagué \\ Ibagué-Colombia \\ Recibido agosto de 2020/Received August, 2020 \\ Aceptado abril de 2021/Accepted April, 2021
}

\begin{abstract}
RESUMEN
Los habitantes de calle son una de las poblaciones con mayor vulnerabilidad dadas características tales como el deterioro de redes de apoyo y vinculación familiar y afectiva, conjunta con dificultades para la integración económica y social, lo que aumenta la percepción de falta de recursos y amplia exposición a situaciones con poco o nulo control. Se plantea que la situación de calle se relaciona con factores de vulnerabilidad cognitiva que pueden facilitar la resignación e inacción, así como atribuciones negativas acerca de la situación y por sí mismo. Se realizó un trabajo de campo consistente en talleres y entrevistas que permitió identificar y aproximar una descripción de factores como la desesperanza, la falta de control de las propias conductas y emociones, la dependencia y culpabilización de otros como una limitación para la toma de responsabilidad, el fatalismo y la derelicción como respuestas emocionales ante la percepción de abandono e inestabilidad, que reproducen la vulnerabilidad ante exigencias externas socioeconómicas tan fuertes como las que comprenden la situación de calle. Se concluye que los resultados expuestos pueden orientar ofertas de intervenciones psicosociales orientadas a minimizar estos factores de vulnerabilidad con tal de aportar a la dignidad de las personas.
\end{abstract}

Palabras Clave: Situación de calle, Desesperanza, Marginalidad, Exclusión Social.

\begin{abstract}
The homeless are one of the populations with greater vulnerability given characteristics such as the deterioration of support networks and familiar and affective bonding, together with difficulties for the economic and social integration, which increases the perception of lack of resources and wide exposure to situations with little or null control. It is proposed that the street situation is related to factors of cognitive vulnerability that can facilitate the resignation and inaction, such as negative attributions on the situation and on itself. A field work consisting of workshops and interviews was carried out that allowed to identify and to approximate a description of factors such as the hopelessness, the lack of control of the own behaviors and emotions, the dependency and culpability of others as a limitation for the taking of responsibility, the fatalism and the dereliction as emotional answers before the perception of abandonment and instability, that reproduce the vulnerability before external socio economic demands as strong as those that understand the street situation. It is concluded that the exposed results can orient offers of psychosocial interventions oriented to minimize these factors of vulnerability with so much to contribute to the dignity of the people.
\end{abstract}

Key Words: Homeless person, Hopelessness, Marginality, Social Exclusión.

\footnotetext{
* Este artículo deriva del proyecto de investigación titulado: Identidad, reconocimiento y marginalidad. Caracterización de la situación de calle en Ibagué, con código 19-497-INT, financiado por la Universidad de Ibagué.

** Autor correspondiente / Corresponding author: juand.zabalas@ gmail.com
} 


\section{INTRODUCCIÓN}

La sociedad contemporánea ha decantado en la formación y mantenimiento de ciudades metrópoli altamente gentrificadas cuyas dinámicas de diferenciación y pluralización se asocian con la aparición de fenómenos de exclusión y segregación social. De entre los múltiples casos y figuras que acogen las sociedades urbanas resulta de especial interés para las ciencias sociales aquellas experiencias que se dan por debajo de la línea de pobreza. En particular, quienes se encuentran desprovistos de recursos y posibilidades de acción, incluso los más básicos, como lo constituye el tener un techo para pasar la noche, una fuente de ingreso o trabajo y redes de apoyo o de vinculación afectiva (Bachiller, 2010; Correa, 2007; Meert et al., 2003; Nieto y Koller, 2015).

Respecto de estas formas extremas de exclusión y marginación, Moreno (2001) resalta características como el bajo nivel de formación, la degradación personal y la ausencia general en la calidad de vida como indicios que permitirán definir este fenómeno. Visto así, el hecho de vivir en la calle es una forma de vida que no es exclusiva (Cabrera, Rubio y Fernández, 2007), pero sí representativa de las ciudades, a la vez que es un signo de la desigualdad y de la vulnerabilidad de la vida en las sociedades contemporáneas (Correa, 2007; Nieto y Koller, 2015). De manera general, se trata de una situación compleja y multidimensional que se relaciona con problemáticas como la exclusión social, la pobreza, la precariedad y el consumo de sustancias psicoactivas (SPA) (Nino, Loya y Cuevas, 2009; Souza, Oliveiras, Chagas y Carvalho, 2016; Suárez-García, 2017), que condiciona las posibilidades de llevar una vida digna y que se establece como una constante en las ciudades occidentales (Universidad Nacional de Colombia y Ministerio de Protección Social [UNAL Y MinProtección], 2007). Por lo que supone la afectación de la dignidad en términos de la limitación de la autodeterminación y de condiciones (i.e. recursos y posibilidades) para llevar a cabo la elección de vida ${ }^{1}$. Se puede evidenciar en el contexto social la falta de equidad en cuanto al acceso a atención, servicios y recursos que permitan suplir las necesidades de esta población (CEPAL, 2010; Quintero, 2008).

Este sector de la población ha recibido diferentes menciones. Desde aquellos que se centran en tener o no un techo adecuado para vivir y su correspondiente denominación de sin techo o personas sin hogar-homeless $-^{2}$ (Bachiller, 2010), pasando por aquellas perspectivas que afirman la existencia de una condición estructuralmente dispuesta que no se reduce al individuo -personas en situación de calle- (del Monte Madrigal, 2018; Makowski, 2010), hasta enfoques centrados en la práctica de habitar la calle, siguiendo así la denominación dada en la legislación y normatividad colombiana -habitantes de calle- (cfr. Gómez, 2015; Ley 1641 de 2013; Ministerio Salud, 2018; Sentencia C-385 de 2014; UNAL y MinProtección, 2007). Lo que resalta, además de la falta de acuerdo en su terminología y fundamento epistémico, es la complejidad del fenómeno que se resiste a ser entendido de manera unívoca a partir de su relación con el marco moral de cada sociedad. En adición, se tiene el aparente acuerdo general frente a que estas personas encarnan una de las poblaciones con mayor vulnerabilidad debido a su aparente falta de recursos y amplia exposición a situaciones con poco o nulo control.

Precisamente, esta aparente falta de control respecto de su situación ${ }^{3}$ e incluso sobre sí mismo (comportamientos, pensamientos y emociones), compone el interés principal del presente trabajo. Se parte del hecho de que la extrema vulnerabilidad implica el deterioro de control (Nino et al., 2009), lo que, sumado a la sucesión de eventos experimentados y evaluados como negativos y situaciones adversas sostenidas a lo largo del tiempo, como una acumulación de desventajas que multiplican las desigualdades (Bayón, 2016; del Monte Madrigal, 2018), podría incidir negativamente en la constitución y el mantenimiento del proyecto y sentido de vida (García-Alandete, Gallego-Pérez y Pérez-Delgado, 2009). En adición, se ha estudiado cómo las atribuciones de incontrolabilidad suelen relacionarse con la desesperanza (Soria, Otamendi, Berrocal, Caño y Rodríguez Naranjo, 2004).

Dentro de las causas comunes de ingreso a la calle, aparece el consumo de SPA (Souza et al., 2016), la violencia intrafamiliar (Evans y Forsyth, 2004), dificultades económicas y desilusiones afectivas (Alcaldía Municipal de Ibagué [Alcaldía Ibagué], 2018). En cuanto a las razones de permanencia en la calle, estas refieren a dificultades económicas, decisión personal, falta de apoyo familiar, algún tipo de enfermedad mental o discapacidad física (Patrício et al., 2019) y consumo de SPA (Alcaldía Ibagué, 2018; Arias y Pamplona, 2015; UNAL Y MinProtección, 2007). 
Sin embargo, no se ahonda mucho en aspectos aprendidos a nivel psicológico tales como percepciones de control y eficacia, sentimientos, creencias y soportes que puedan influir en la permanencia en calle, entre otros. El presente trabajo busca adentrarse en la desesperanza aprendida y el fatalismo, como factores aprendidos, que tienen una incidencia en la permanencia en calle. De ahí que se busque describir las relaciones entre la atribución de culpa y la falta de control percibida de emociones y conductas, a la vez que se espera identificar la derelicción como sentimiento de abandono y resignación que marca la percepción de las propias capacidades para afrontar la situación vivida.

Como se mencionó antes, el presente estudio busca complementar el enfoque de las estructuras de oportunidades como elemento explicativo de la reproducción de la desigualdad (Kaztman, 1999), aportando a aquellos factores subjetivos que inciden en el aprovechamiento o no de las limitadas oportunidades de las que se disponen en la calle. Para ello se desarrollará brevemente acerca del concepto de marginalidad y los posibles aportes que este pueda implicar para entender las formas en que se configuran las vulnerabilidades de los habitantes de calle.

Si bien es cierto que la literatura presenta la relación entre factores materiales y relacionales (pobreza, falta de servicios de salud, exposición a violencias sexuales y agresiones de diverso tipo) con la aparición de trastornos psicológicos como la desesperanza, la depresión, el consumo de SPA, entre otros, el presente texto tiene por intención describir algunos de estos desde la perspectiva de factores que predisponen para la vulnerabilidad, a la par que busca poner en manifiesto la necesidad de aumentar la investigación al respecto poniendo énfasis en aspectos poco evidenciados como el sentimiento de culpa y su uso funcional, el sentimiento de abandono y de encierro o derelicción. De ahí que el presente sea un estudio descriptivo, y la posibilidad de comparación escape a las pretensiones y posibilidades de este.

FACTORES DE VULNERABILIDAD COGNITIVA DE LA HABITANZA EN CALLE

La vida en la calle no es natural y comprende procesos de aprendizaje y adaptación que requieren ser explorados. Algunas aproximaciones refieren al desarrollo de una identidad marginal, tal como lo sostiene Berho (2006; 2010), la que implica distintas fases marcadas en el tiempo a partir de hitos en la adaptación al estilo de vida. Esto implica esquemas cognitivos y conductuales desarrollados y aprendidos que contribuyen al establecimiento de cierto tipo de relaciones entre el individuo y su entorno ambiental y social, siendo así que se favorece el desarrollo de la vulnerabilidad, sin que sea posible establecer causas únicas o determinantes.

Los factores de vulnerabilidad cognitivos se entienden latentes y se presentan a partir de experiencias previas significantes que resulta una enseñanza, y se ven reflejados en la forma de pensar y actuar de una persona en el futuro (Abramson, Metalsky y Alloy, 1989; García-Alandete et al., 2009). Al respecto, los habitantes de calle, lejos de indicar una única experiencia de ruptura que marca un antes y un después en sus vidas, suelen reportar múltiples experiencias que los sumieron en la precariedad y que pueden percibirse como negativas (del Monte Madrigal, 2018), estas pueden ocasionar que los participantes tengan una percepción negativa hacia el futuro y no realicen actos para disminuir su problemática, por esta razón, los factores aprendidos pueden tener una importante incidencia en la permanencia en calle.

Es posible entender la habitanza en calle como un fenómeno caracterizado por la marginalidad y exclusión social, es decir, la ruptura respecto de las condiciones y expectativas de la sociedad mayoritaria. En las décadas recientes, las teorías de la marginalidad han recibido una renovada atención, en la medida en que han posibilitado la lectura de fenómenos sociales, mayoritariamente urbanos, de exclusión social cada vez más profundos y complejos. Cortés (2012) afirma como central a este retorno del concepto de marginalidad, la preocupación por las crecientes dificultades para la integración de personas y grupos considerados "periféricos" de la sociedad, por lo que la exclusión resulta "de un proceso de acumulación de desventajas que corroe la relación individuo-sociedad y con ella las condiciones de pertenecimiento y de solidaridad mismas" (p. 232).

Al respecto, autores como Germani (1973) afirman que es posible entender la marginalidad a partir de sus causas (e.g. desempleo, falta de vivienda o vivir a la periferia de la ciudad, diferencias culturales, etc.), pero que no se reduce a la pobreza. De manera similar, Vekemans (citado por Cortés, 2012) entiende que la marginalidad se distancia de la pobreza en su radicalidad, en tanto 
implica la distinción entre la sociedad establecida y participante y aquellas facciones marginadas. De allí que una primera característica esté en la limitación de la participación social, que puede entenderse a nivel económico, cultural, político, etcétera.

Esta limitación a la participación debe ser matizada, pues no es posible determinarla como absoluta, más bien, siguiendo a los autores, se entiende como una privación relativa en tanto no se puede satisfacer del todo o en forma eficiente las condiciones de vida que le permitan desempeñarse, relacionarse y seguir el comportamiento acostumbrado que se espera por el simple hecho de formar parte de la sociedad (Germani, 1973; Townsend, 2003). Esto implica la existencia de un marco moral normativo que establece algunos desempeños mínimos con tal de ser parte de la sociedad, los que no logran satisfacerse, de ahí que la marginalidad se entienda relativa, "relacional y negativa (carencia), pues el marginal está fuera de las decisiones que modelan la sociedad y de las estructuras con las que ella se crea a sí misma" (Cortés, 2012, p. 232). La marginalidad, analíticamente hablando, habría que entenderla de manera multidimensional, esto es, que es posible estar marginado en un nivel o dimensión (e.g. económico: desempleo) pero integrado en otro (e.g. familiar), así que se entiende como un fenómeno complejo en el que la mayor marginación estaría dada por una mayor cantidad de dimensiones signadas con la exclusión.

La marginalidad también se caracteriza por la dificultad o incapacidad de gozar de derechos sociales (Moreno, 2001). La persona o grupo no cuenta con servicios, ni bienes sociales, ni están incorporadas a las relaciones de producción; dándose así dos tipos de marginación: la objetiva donde el individuo o grupo está marginado con relación al sistema total, del poder económico, del plano cultural, de los valores aceptados, de la distribución de poder y del plano social; y la marginación subjetiva se basa en los mecanismos conductuales que regulan la vida del grupo, donde el individuo se convierte en el regulador de procesos de adaptación con el mundo social y con la naturaleza. Esta última implica la existencia de factores subjetivos, quizá individuales o cognitivos, que propenden por la marginación.

En cuanto a la dimensión psicológica, Germani (1973) deja planteada varias ideas concernientes a las atribuciones que los individuos hacen acerca de su propia situación, como una asunción de culpa que se refuerza por la imposibilidad de

adecuación respecto del marco normativo común y hegemónico. Es decir, la persona asume que la causa de su marginación es por alguna deficiencia suya o incluso porque ese es su lugar en el mundo, por lo que se da un deterioro a nivel de autoestima. A propósito, Kaztman (1999) relaciona las formas de vulnerabilidad tendientes a la marginalidad, que parten de "Malas condiciones habitacionales, insuficientes activos en recursos humanos dentro de las familias, alimentación escasa y de poca calidad" (p. 27), con la aparición de factores psicológicos y sociales como la

\begin{abstract}
...alta permeabilidad a los vicios sociales, precario control y atención de la salud y una baja autoestima... [que se acompañan de] ... contenidos mentales: una visión desesperanzada, la ausencia de imágenes que asocien esfuerzos con logros y el convencimiento que con los activos que poseen no hay beneficios en la integración a la sociedad (Kaztman, 1999, p. 27).
\end{abstract}

Por lo que la afectación a la autoestima, la desesperanza, entre otros, sobreviene a los factores materiales ${ }^{4}$. Así que, los diferentes actores, marginados o no, ven el marco normativo como algo natural e indiscutible, lo que genera una reducción de las posibilidades y los ánimos para la integración social.

Vista así, la marginalidad implicaría el situarse fuera de lo instituido y así quedar excluido del sistema (Berho, 2006; 2010), limitando la participación del estatuto ideológico hegemónico y del goce de derechos vinculados al mismo. Llegando incluso a desestimar el uso de servicios sociales en casos en que la situación de calle se hace crónica (Nino, Loya y Cuevas, 2009). Para Moreno (2001), esto se caracteriza por la percepción que hace el sujeto de su imposibilidad para afrontar las exigencias del entorno, que se marca como impotencia a la hora de cambiar su situación adversa. El actor social ve que no tiene las formas para mejorar su condición, por lo que, a causa del (precario) reconocimiento de sus propias capacidades y una ponderación negativa de sus posibilidades, se tiende a la inacción frente a la situación adversa, lo que redunda en un pesimismo generalizado, muchas veces basado en experiencias negativas de violencia o menosprecio vividas de forma precedente.

Por su parte, Martín-Baró (citado por Blanco y Díaz, 2007) acuña la noción de fatalismo, en donde relaciona el pesimismo con la inacción de 
las poblaciones más golpeadas por las situaciones desfavorables como una forma estratégica de evitar que las condiciones empeoren, sin embargo, la inacción impide que se pueda buscar el cambio a mejor, lo que aporta a la inmovilidad social y a la sensación de encierro. Además, el pesimismo parece contener a la desesperanza aprendida, que se caracteriza, además de lo ya mencionado, por la dificultad para trazar planes de vida a futuro y un precario control de conductas y emociones (Beck y Weissman, 1974; González y Hernández, 2012).

La desesperanza se puede identificar en la falta de motivación para resolver un problema, siendo la desesperanza un factor de vulnerabilidad cognitiva relacionada con la depresión (García-Alandete et al., 2009) y que suele acompañarse de culpabilización por la situación, además de la consideración de no poder salir de esta a partir de la tendencia a hacer evaluaciones negativas acerca de acontecimientos o situaciones adversas, lo que se relaciona con atribuir consecuencias negativas y asumir cualidades negativas sobre sí mismo (García-Alandete et al., 2009; González y Hernández, 2012).

En adición, Martuccelli y Santiago (2017) plantean el sentimiento de derelicción, producto de situaciones en que los individuos sometidos a pocas o nulas oportunidades de cambiar su situación dan cuenta de un temor por no poder salir, denotado con aburrimiento. Al respecto, se tiene que las múltiples precariedades que caracterizan la situación de calle se dan de manera acumulada y multidimensional en la biografía de cada individuo, por lo que se genera la sensación de estar atrapado y sin mayores perspectivas de cambio (Biscotto, Jesus, Silva, Oliveira y Merighi, 2016; del Monte Madrigal, 2018). Esto hace probable la inacción, o por otra parte, propicia la ocurrencia de conductas que van en contravía de lo establecido socialmente como adecuado y que por tanto podría redundar en el estereotipo de desadaptación social que ya se les aplicaba (Elías y Scotson, 2016). Este es un punto con cierta reiteración en los trabajos de Martuccelli. La derelicción es la categoría a nivel subjetivo que le permite describir la experiencia del individuo respecto de las contingencias recreadas por elementos estructurales a nivel histórico y social por los que ha de pasar en su proceso de individuación, toda vez que dicha contingencia o prueba implica la posibilidad de fracasar en el desafío (Martuccelli, 2007), aparece la derelicción como el correlato emocional que acompaña el saberse perdedor del mundo y estar excluido y con oportunidades reducidas.

En definitiva, aunque hay una amplia variedad de formas de vida asociadas con la calle, que presentan variaciones conforme el grado de permanencia o de marginalidad (Berho, 2006; 2010), a los factores de riesgo asociados a las diferencias sexuales (Biscotto et al., 2016; Evans y Forsyth, 2004; Meyer, 2015; Souza et al., 2016), la proporción de actividades realizadas en este espacio, se entiende de manera general que la situación de calle conlleva a la exposición de un sinnúmero de incertidumbres ligadas a la satisfacción de necesidades básicas, a las posibilidades de salir de esta, establecer y avanzar en el proyecto de vida (Nino et al., 2009). Los habitantes de calle suelen ser objeto y sujeto de vejaciones y menosprecios que ponen en riesgo su integridad física, psíquica y generan daños a nivel material, relacional y simbólico (del Monte Madrigal, 2018; Ministerio de desarrollo social y familia [MIDESO], 2012). A nivel psicológico prevalecen la depresión, ansiedad, estrés, ideaciones suicidas, pérdida de sentido de vida, insomnio, aislamiento social, uso de drogas, abuso sexual (Nino et al., 2009; Patrício et al., 2019). Se entiende que los habitantes de calle suelen presentar una aceleración en el proceso natural de envejecimiento y deterioro biopsicosocial (MIDESO, 2012; Patrício et al., 2019).

En resumen, aunque son perspectivas plurales, parecen coincidir en la inacción, la evaluación negativa de las propias capacidades y recursos para cambiar la situación adversa, la percepción de falta de control de la misma, el sentimiento de abandono y el temor de encierro, junto con la culpabilización.

\section{METODOLOGÍA}

La investigación se realizó con el fin de identificar y describir algunos de los factores de vulnerabilidad cognitiva, entendiendo que podría ayudar a fundamentar futuras indagaciones de manera más precisa. Esta investigación se realizó bajo los principios éticos de beneficencia y no maleficencia, siguiendo la aprobación del comité de investigaciones de la institución de aval y de directores de los hogares de paso, en donde se percató de no afectar a ninguno de los participantes. Con el fin de velar por el derecho a la dignidad humana de los participantes, las entrevistas realizadas se hicieron bajo consentimiento informado y, según instrucción de los participantes, se emplean seudónimos con tal 
de proteger su identidad, como medida de respeto a su confidencialidad.

\section{Diseño}

Respecto del diseño, se tuvieron en cuenta dos consideraciones, la primera, respecto de su alcance descriptivo, para ello se contó con un diseño no experimental y transeccional que privilegió el trabajo en terreno (Hernández y Mendoza, 2018). Esto permitió aproximarse al fenómeno de estudio en la calle misma, tratando de propiciar la apertura a la conversación por medio de entrevistas semiestructuradas y talleres (en los casos en que fue posible asignar una locación).

Una segunda consideración está en el grado de flexibilidad del proceso de investigación. En la medida en que se consideró la investigación desde una perspectiva dialéctica, cuya función está en propiciar espacios para la interpretación de la vivencia como fundamento de la experiencia, entonces, se planteó el proceso de investigación bajo un diseño que aportó la posibilidad de ajuste. El diseño se consideró abierto, basado en un dispositivo probatorio que se perfeccionó a medida en que se dio el trabajo de campo (Cottet, 2014), e intersubjetivo, evaluando el recurso a la experiencia de los participantes como fundamento para la construcción de los datos.

En definitiva, se buscó propiciar instancias de interlocución que permitieran compartir la experiencia de los participantes con el equipo de investigación, de esta forma, se identificaron algunos factores que permitieron la descripción superficial de sus relaciones. No se pretendió agotar ni reducir el fenómeno a explicaciones deterministas y causalistas (Cunda y Silva, 2020).

\section{Técnicas}

El trabajo se ordenó en dos momentos, en el primero se propuso realizar un taller de Árbol de sueños y metas [ASM] con un grupo de informantes encontrados en el Hogar de paso San Francisco de Asís. Debido a las características de la institución, todos los participantes fueron hombres, con bajo o nulo consumo de SPA reportado. Este taller permitió identificar algunos elementos básicos tales como sus metas, recursos y dificultades en el marco de la relación de proyección presente y futura de su vida (Soliz y Maldonado, 2006).

Esta técnica permite dialogar a partir de la perspectiva de los participantes acerca de los problemas que se están presentando en su día a día en tanto individuos y grupo, además, facilita el consenso de causas percibidas y de posibles rutas para alcanzar una solución. En este caso, el taller consistió en identificar de manera individual algunos de sus miedos y situarlos en las raíces de una figura de árbol previamente dispuesta. De igual forma, se escribieron sus sueños o metas y se posicionaron en las ramas del árbol. Acto seguido, en la parte del tronco del árbol se disponen los recursos que necesitan para cumplir con sus metas, así como los compromisos que consideran que deben realizar para vencer los miedos (Soliz, Maldonado, 2012). Finalmente, se ponen en común las elaboraciones individuales con tal de recibir retroalimentación del grupo.

Se prestó especial atención a los participantes que no mencionaron sueños y metas, así como a aquellos que manifiestan no saber cómo solucionar los impedimentos que se les presentan para cumplirlos. Con estos últimos informantes y con otros con quienes no fue posible realizar el taller, se adelantó algunas entrevistas semiestructuradas (Díaz-Bravo, Torruco-García, Martínez-Hernández y Varela-Ruiz, 2013; Martínez, 2015), con tal de ahondar en las razones de permanencia en calle, en los aspectos percibidos que los limitan para salir de esta y sus sentimientos hacia el futuro.

El uso de la entrevista se da como forma de recurrir a la experiencia de los habitantes de calle, esto implica plantear contingencias que permitan la conversación. Los “discursos se generan en una situación real donde hay una interacción o juego comunicativo" (Martinic, 1992, p. 5). Se entiende que mediante la conversación se hace posible la construcción de sentido, siendo la entrevista un escenario propicio para ello (Rapley, 2014). Así, "las situaciones de entrevistas [...] son discursos que se producen en interacciones y que develan ciertas estructuras que, a la vez, inciden en la organización de los sentidos y enunciación del discurso en la trayectoria de la interacción" (Martinic, 1992, p. 6).

Siguiendo a Ortiz (2007), la entrevista semiestructurada se basa en el diálogo, como forma primaria de interlocución a partir de ciertas preguntas que pueden variar en orden y formulación. La discusión se orienta a partir de tópicos de conversación previamente estipulados. La combinación de tipos de preguntas permite dinamizar la entrevista a la vez que mantiene un interés investigativo claro; su principal característica es la flexibilidad y la posibilidad de ajuste del orden y combinación de tipos de preguntas. 
En este caso, los tópicos derivaron de los resultados iniciales del taller ASM, de esta manera, se cuestionó acerca del tiempo de permanencia en calle, los motivos o eventos que dispararon la llegada a la calle y las posibles explicaciones que tiene para esos motivos o eventos, centrándose en la fuente o causa que lo llevó a asumir la calle, así como su papel en dicho proceso. En relación con su situación y condiciones de vida actuales, se indagó acerca de sus sensaciones y sentimientos al respecto, los elementos centrales de su conformidad o disconformidad con el estilo de vida que lleva actualmente. Finalmente, se abordaron las consideraciones frente a sus deseos y posibilidades para cambiar su situación actual, centrándose en sus medios propios y en los activos provenientes de terceros.

\section{Estrategia de análisis}

El proceso de análisis implicó una fase inicial a partir de la información obtenida del taller ASM, que permitió plantear algunas categorías iniciales basadas en los sueños o metas, los recursos, los impedimentos o dificultades y las soluciones percibidas.
Las entrevistas fueron transcritas en su totalidad y se aplicaron medidas de seguridad (se borraron datos personales de identificación y toda información que pudiera ser comprometedora). Para la confección de códigos se realizaron lecturas consecutivas de cada documento, luego se realizó un primer momento de consenso entre observadores, que permitió generar códigos independientes entre sí y que fueran sensibles a las dificultades (impedimentos) y facilidades (oportunidades/recursos) de los que daban razón los participantes en relación con sus metas o sueños. Luego se realizó la codificación temática del conjunto de documentos (Gibbs, 2012). Finalmente, los diferentes códigos se agruparon en categorías a partir de dos principios, primero, la diferenciación entre unos y otros a nivel temático, de tal manera que se lograran conjuntos autocontenidos; segundo, se clasificaron los códigos a partir de la consideración de las concurrencias entre unos y otros en cuanto a citas compartidas (Andreu, 2002; Martínez, 2006), acto seguido, se identificaron las relaciones entre categorías y sus partes, lo que permitió la confección del sistema de categorías (ver Figura 1).

\section{Figura 1}

\section{Factores de vulnerabilidad. Elaboración propia.}

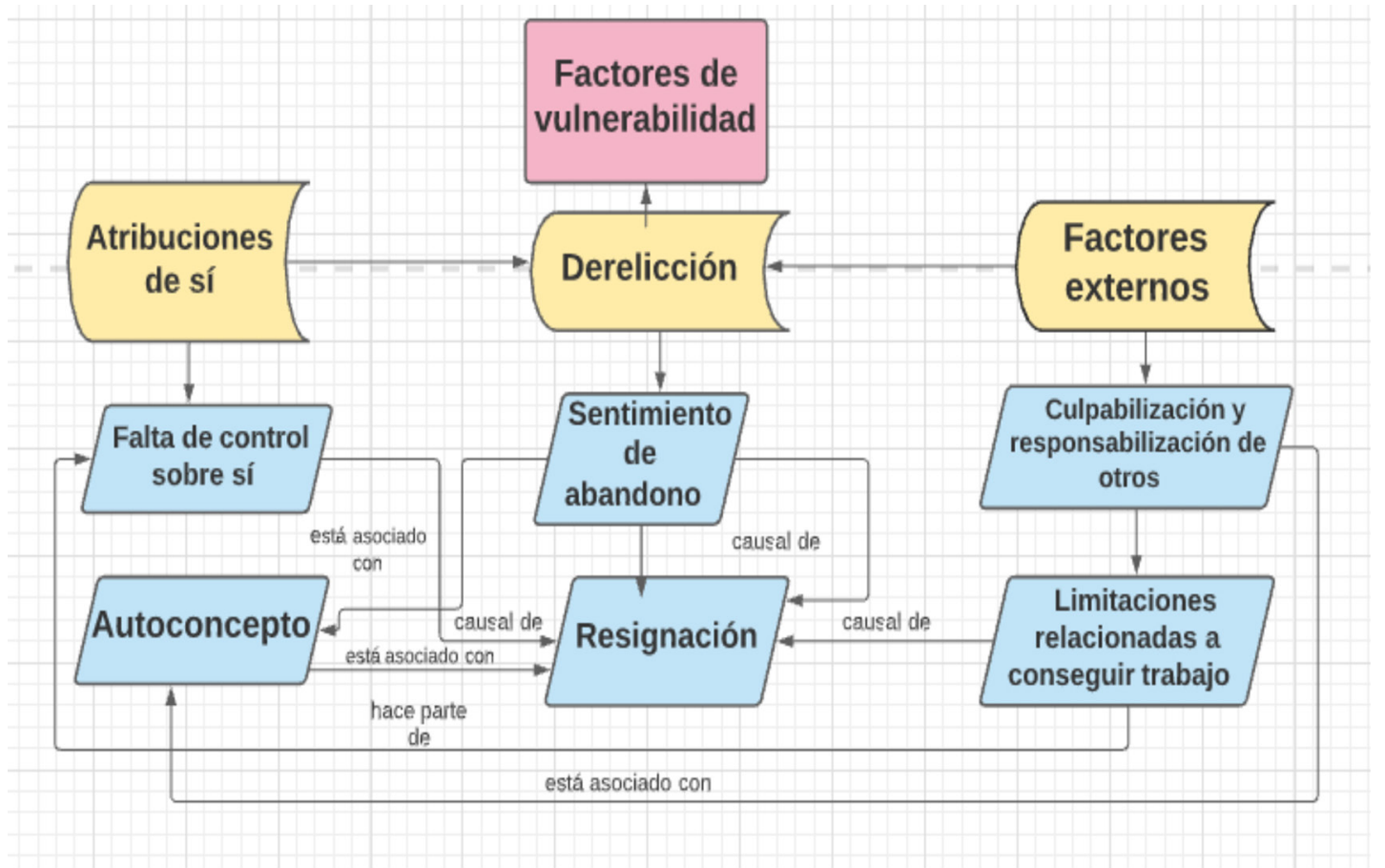




\section{Participantes}

Entendiendo que es imposible abarcar la totalidad de las formas de vida que tienen lugar y tiempo en las calles, se optó, inicialmente, por trabajar con personas mayores de edad que se autorreconocieran como habitantes de calle. Se tuvo en cuenta criterios como el hecho de que hubieran pasado la noche en la calle al menos una vez en el último mes, que residan en la ciudad de Ibagué. Se buscó diversificar la muestra con individuos que hicieran algún uso de los servicios sociales e institucionales de la ciudad (hogares de paso, jornadas de salud de la alcaldía, etc.) y otros que no hicieran uso de estas instancias. También se trató de asegurar la participación de al menos una mujer. No se tuvo en cuenta el tiempo de permanencia en calle como un criterio muestral.

Se contó con un grupo de 11 personas, ocho hombres y tres mujeres (ver Tabla 1). Con edades comprendidas entre los 33 y 75 años, presentan además un tiempo de permanencia en calle entre 3 a 45 años, por lo que puede considerarse que la muestra se ubicó entre lo que Berho (2006; 2010) entiende como permanentes. Dentro de sus motivos reportados de llegada a la calle, se identifican los problemas de consumo de SPA, dificultades económicas, pérdida de vivienda, ruptura de lazos familiares, e incluso precariedad de larga data desde la niñez. En cuanto a algunos de los factores de permanencia en calle, los participantes reportan no tener contacto con sus familiares y, de manera minoritaria, el consumo de SPA.

Los participantes fueron contactados a partir de jornadas en el parque Andrés López de Galarza ${ }^{5}$, adelantadas por el Semillero Desde el Margen de la Universidad de Ibagué, y otros por medio del Hogar de paso para hermanitos de la calle San Francisco de Asís ${ }^{6}$. La muestra se limitó a la disponibilidad, que estuvo sujeta a la voluntad de participar. Aunque se buscó obtener información base acerca de ellos (de su edad, motivos de llegada y tiempo de permanencia en calle, consumo de SPA, etc.), estos datos no siempre fueron reportados. Negarse a aportar esta información de base no implicó su exclusión del estudio, en tanto se consideró como prioridad el establecimiento de canales de conversación (ASM y entrevista) para la obtención de la información.

\section{ANÁLISIS DE RESULTADOS}

Dentro de los resultados obtenidos del taller ASM, se evidencia que los participantes emiten expresiones respecto de sus perspectivas acerca del futuro, sus metas y limitaciones para salir de su condición actual (ver Tabla 2). De manera general, es evidente que sus metas y sueños se refieren a la dimensión laboral y de vinculación familiar y afectiva, planteando a su vez las ansias de estabilidad. Lo anterior se contrasta con aquellos impedimentos reconocidos que se agrupan en elementos que, en su mayoría, son inherentes o propios de sí mismos, como su capacidad de regulación comportamental y emocional, su edad, estado de salud, nivel educativo, existiendo una mención a impedimentos externos como la escasa oferta de trabajo o a la no existencia de una familia.

A partir de la información obtenida del taller ASM y de las entrevistas, se procedió a establecer relaciones entre las narrativas. Se configuraron tres categorías que anclan los datos y permiten su lectura, la primera tiene que ver con la forma en que los participantes caracterizan las situaciones que afrontan actualmente, es decir, el hecho de habitar la calle, lo que cobra énfasis en las supuestas causas de su permanencia, como falta de oportunidades laborales y de afiliación, la dificultad para entender y predecir las situaciones sociales y el ubicar la responsabilidad de manera externa mediante la culpabilización y la dependencia de otros. Una segunda categoría son las atribuciones sobre sí, que comprende las afectaciones al autoconcepto en tanto da cuenta de sus cualidades, características y recursos con los que logran o no afrontar la situación de calle, además están la falta de control de sí que tiene que ver con la deficiencia para la propia regulación. Por último, está la derelicción, que se entiende como el sentimiento de abandono por parte de los otros y toma un grado más profundo con la resignación ante la situación adversa, que podría entenderse como una forma de abandono de sí. Estas categorías están estrechamente relacionadas por lo que se entienden como parte de un mismo constructo. A continuación se presentarán los resultados ordenados por categorías y subcategorías para al final evidenciar las relaciones entre ellas.

\section{Evaluación de la situación}

De manera general, se encontró que se reconoce la situación de calle como adversa a causa de la dificultad que esta implica para lograr satisfacer las necesidades básicas y la ruptura parcial o total con grupos familiares, lo que causa sufrimiento en ellos, por lo que se califica de indeseable. Es de 


\section{Tabla 1}

Relación de participantes

\begin{tabular}{|c|c|c|c|c|c|c|c|}
\hline Nombre & Edad & Sexo & $\begin{array}{c}\text { Años } \\
\text { en calle }\end{array}$ & $\begin{array}{c}\text { Motivo por el que } \\
\text { habita } \\
\text { en la calle }\end{array}$ & $\begin{array}{l}\text { Relación con } \\
\text { familiares }\end{array}$ & Consumo de SPA & $\begin{array}{l}\text { Movilización a } \\
\text { otras ciudades }\end{array}$ \\
\hline Alejandro $(\alpha+)$ & 63 años & M & 45 años & $\begin{array}{l}\text { Problemas } \\
\text { económicos, } \\
\text { especialmente } \\
\text { por su edad. }\end{array}$ & No reporta. & $\begin{array}{l}\text { No consume } \\
\text { actualmente. }\end{array}$ & $\begin{array}{l}\text { Originario y residen- } \\
\text { te de Ibagué. }\end{array}$ \\
\hline Héctor $(\alpha+)$ & 33 años & M & $\begin{array}{l}\text { Más de } 7 \\
\text { años. }\end{array}$ & $\begin{array}{l}\text { Problemas fami- } \\
\text { liares. Consumo } \\
\text { de SPA. }\end{array}$ & $\begin{array}{l}\text { No tiene contacto } \\
\text { con familia. }\end{array}$ & $\begin{array}{l}\text { No consume } \\
\text { actualmente. }\end{array}$ & No reporta. \\
\hline Jaime $(\alpha \beta+)$ & 45 años & M & 25 años & $\begin{array}{l}\text { Consumo de } \\
\text { SPA y problemas } \\
\text { económicos. }\end{array}$ & No reporta. & $\begin{array}{l}\text { Consume drogas, } \\
\text { no especifica } \\
\text { cuáles. }\end{array}$ & $\begin{array}{l}\text { Originario de } \\
\text { Antioquia. Estuvo un } \\
\text { tiempo en Bogotá. }\end{array}$ \\
\hline Gustavo $(\alpha \beta+)$ & 43 años & M & 37 años & No reporta. & $\begin{array}{l}\text { Tiene esposa e } \\
\text { hijos, pero hace } \\
\text { más de } 10 \text { años } \\
\text { que no se comu- } \\
\text { nica con ellos. }\end{array}$ & $\begin{array}{l}\text { No consume } \\
\text { actualmente. }\end{array}$ & $\begin{array}{l}\text { Se movilizó de } \\
\text { Armenia a Ibagué. }\end{array}$ \\
\hline César $(\alpha \beta+)$ & 54 años & M & 3 años & $\begin{array}{l}\text { Problemas perso- } \\
\text { nales y pérdida de } \\
\text { su casa. }\end{array}$ & $\begin{array}{l}\text { La mayoría de } \\
\text { su familia murió. } \\
\text { Tiene dos hijos, } \\
\text { pero no cuenta } \\
\text { con su apoyo. }\end{array}$ & $\begin{array}{l}\text { Consumió drogas } \\
\text { durante } 30 \text { años. } \\
\text { Actualmente no } \\
\text { consume. }\end{array}$ & $\begin{array}{l}\text { Se movilizó de } \\
\text { Bogotá a Ibagué. }\end{array}$ \\
\hline Yesid $(\alpha \beta+)$ & 75 años & M & 45 años & $\begin{array}{l}\text { Nunca ha poseí- } \\
\text { do recursos para } \\
\text { pagar un lugar es- } \\
\text { table para dormir. }\end{array}$ & $\begin{array}{l}\text { No tiene con- } \\
\text { tacto con sus } \\
\text { familiares. }\end{array}$ & No reporta. & $\begin{array}{l}\text { Reside en Ibagué. } \\
\mathrm{N} \text { o r e p o r } \mathrm{t} \text { a } \\
\text { movimientos. }\end{array}$ \\
\hline Carlos $(\alpha \beta+)$ & 58 años & M & 25 años & $\begin{array}{l}\text { Problemas } \\
\text { familiares y } \\
\text { económicos. }\end{array}$ & $\begin{array}{l}\text { No tiene contacto } \\
\text { con familia. }\end{array}$ & $\begin{array}{l}\text { No consume } \\
\text { actualmente. }\end{array}$ & $\begin{array}{l}\text { Originario de Perú. } \\
\text { Estuvo en Bogotá. }\end{array}$ \\
\hline Rosalía ( $\beta+)$ & 62 años & $\mathrm{F}$ & $\begin{array}{l}\text { Alterna entre } \\
\text { el apoyo } \\
\text { familiar y la } \\
\text { calle. }\end{array}$ & No reporta. & No reporta. & No reporta. & $\begin{array}{l}\text { Reside en Ibagué. } \\
\mathrm{N} \text { o r e p o r } \mathrm{t} \\
\text { movimientos. }\end{array}$ \\
\hline Rolo $\left(\beta^{*}\right)$ & $\begin{array}{l}\text { Aprox. } 45 \\
\text { años }\end{array}$ & M & $\begin{array}{l}\text { Desde los } \\
13 \text { años es } \\
\text { habitante en } \\
\text { calle. }\end{array}$ & $\begin{array}{l}\text { Rompió lazos } \\
\text { con sus familia- } \\
\text { res por ser alguien } \\
\text { conflictivo. } \\
\text { Destaca que el } \\
\text { consumo de SPA } \\
\text { hasido un motivo } \\
\text { recurrente. }\end{array}$ & $\begin{array}{l}\text { Posee contacto } \\
\text { con su hija. }\end{array}$ & Marihuana y licor & $\begin{array}{l}\text { Ha estado en nueve } \\
\text { países distintos. Se } \\
\text { establece en Ibagué, } \\
\text { porque considera } \\
\text { que "es una ciudad } \\
\text { cómoda para el } \\
\text { vago". }\end{array}$ \\
\hline Paola $\left(\beta^{*}\right)$ & 46 años & $\mathrm{F}$ & $\begin{array}{l}\text { Desde los } \\
14 \text { años se } \\
\text { desempe- } \\
\text { ña como } \\
\text { trabajadora } \\
\text { sexual. }\end{array}$ & $\begin{array}{l}\text { Por falta de re- } \\
\text { cursos, desde su } \\
\text { infancia ha ejer- } \\
\text { cido el trabajo } \\
\text { sexual. }\end{array}$ & $\begin{array}{l}\text { Vive con sus dos } \\
\text { hijos menores de } \\
\text { edad. }\end{array}$ & No reporta. & $\begin{array}{l}\text { Reside en Ibagué. No } \\
\text { reporta movimientos }\end{array}$ \\
\hline
\end{tabular}




\section{Continuación Tabla 1}

\begin{tabular}{|c|c|c|c|c|c|c|c|}
\hline Nombre & Edad & Sexo & $\begin{array}{c}\text { Años } \\
\text { en calle }\end{array}$ & $\begin{array}{c}\text { Motivo por el que } \\
\text { habita } \\
\text { en la calle }\end{array}$ & $\begin{array}{l}\text { Relación con } \\
\text { familiares }\end{array}$ & Consumo de SPA & $\begin{array}{l}\text { Movilización a } \\
\text { otras ciudades }\end{array}$ \\
\hline Ana $\left(\beta^{*}\right)$ & 36 años & $\mathrm{F}$ & $\begin{array}{l}\text { Desde los } \\
14 \text { años se } \\
\text { desempe- } \\
\text { ña como } \\
\text { trabajadora } \\
\text { sexual. }\end{array}$ & $\begin{array}{l}\text { Vivió con su } \\
\text { abuela hasta los } \\
14 \text { años. A esa } \\
\text { edad empezó a } \\
\text { desempeñarse } \\
\text { como trabajadora } \\
\text { sexual. }\end{array}$ & $\begin{array}{l}\text { Tiene seis hijos, } \\
\text { vive con sus dos } \\
\text { hijas menores de } \\
\text { edad. }\end{array}$ & No reporta. & $\begin{array}{l}\text { Reside en Ibagué, } \\
\text { pero en ocasiones } \\
\text { se moviliza a otras } \\
\text { ciudades en busca } \\
\text { de mayores oportu- } \\
\text { nidades monetarias. }\end{array}$ \\
\hline
\end{tabular}

Convenciones: $\alpha$ (participó del taller ASM), $\beta$ (participó de entrevista), + (Hogar de paso), * (Parque Galarza). Fuente: Elaboración propia.

Tabla 2

\section{Resultados del taller ASM}

\begin{tabular}{|c|c|c|c|}
\hline Nombre & Metas y sueños a futuro & Impedimentos & Solución de impedimentos \\
\hline $\begin{array}{l}\text { Carlos } \\
\text { (58 años) }\end{array}$ & $\begin{array}{l}\text { - Tener un hogar. } \\
\text { - Tener un trabajo estable. }\end{array}$ & $\begin{array}{l}\text { - Mal manejo de emociones. } \\
\text { - Inestabilidad laboral. } \\
\text { - Salud. } \\
\text { - Avanzada edad. }\end{array}$ & $\begin{array}{l}\text { - Recibir apoyo psicoterapéutico, } \\
\text { espiritual y social. } \\
\text { - Buscar alternativas laborales. } \\
\text { - Tener apoyo familiar. } \\
\text { - Solucionar problemas } \\
\text { personales. }\end{array}$ \\
\hline $\begin{array}{l}\text { Héctor } \\
(33 \text { años })\end{array}$ & $\begin{array}{l}\text { - Recuperar a mi familia. } \\
\text { - Estudiar para salir adelante. } \\
\text { - Dejar las drogas, como ahora } \\
\text { lo estoy haciendo. }\end{array}$ & $\begin{array}{l}\text { - Falta de estudio. } \\
\text { - Mal comportamiento. } \\
\text { - No tener contacto con mi } \\
\text { familia. }\end{array}$ & $\begin{array}{l}\text { - Estudiar. } \\
\text { - Comportarme. } \\
\text { - Ser mejor cada día. } \\
\text { - Trabajar como cocinero del } \\
\text { hogar de paso. }\end{array}$ \\
\hline $\begin{array}{l}\text { Gustavo } \\
(43 \text { años })\end{array}$ & - Mejorar mi calidad de vida. & $\begin{array}{l}\text { - La mayor dificultad es mi } \\
\text { enfermedad. }\end{array}$ & - No reporta \\
\hline $\begin{array}{l}\text { César } \\
\text { (54 años) }\end{array}$ & $\begin{array}{l}\text { Encontrar una labor para estar } \\
\text { ocupado. }\end{array}$ & - No tener apoyo. & $\begin{array}{l}\text { - Necesito una recomendación la- } \\
\text { boral, porque yo puedo hacerlo. }\end{array}$ \\
\hline $\begin{array}{l}\text { Jaime } \\
\text { (45 años) }\end{array}$ & $\begin{array}{l}\text { - Encontrar una oportunidad } \\
\text { laboral. }\end{array}$ & $\begin{array}{l}\text { - Falta de oportunidades } \\
\text { laborales. }\end{array}$ & $\begin{array}{l}\text { - Tratar de ser paciente para } \\
\text { encontrar las vacantes. }\end{array}$ \\
\hline $\begin{array}{l}\text { Yesid } \\
\text { (75 años) }\end{array}$ & - Ser buen trabajador & $\begin{array}{l}\text { - No tengo trabajo. } \\
\text { - No tengo familia. }\end{array}$ & - No reporta \\
\hline $\begin{array}{l}\text { Alejandro } \\
(63 \text { años })\end{array}$ & $\begin{array}{l}\text { - Trabajar en cualquier } \\
\text { actividad. }\end{array}$ & $\begin{array}{l}\text { - Es difícil por mi avanzada } \\
\text { edad. }\end{array}$ & $\begin{array}{l}\text { - Conseguir un trabajo "suave", } \\
\text { como guardia de seguridad o } \\
\text { similar. }\end{array}$ \\
\hline
\end{tabular}

Fuente: Elaboración propia. 
resaltar que los participantes reconocen las múltiples limitaciones en la obtención de trabajo y en la imposibilidad de obtener otros trabajos, por la falta de oferta de empleo; a su vez, también existen casos en que se evidencia que no contar con familiares vivos o conocidos genera un estrechamiento de opciones de acción; limitaciones por las que los habitantes manifiestan que no han podido conseguir sus objetivos. Las justificaciones que a partir de las entrevistas se encontraron abarcan atribuciones a factores externos a ellos mismos (estructurales y situacionales).

Otra limitación percibida está en la remuneración injusta y maltrato en sus trabajos debido a su condición, varios habitantes también afirman que muchas personas se aprovechan de ellos y no les pagan lo justo por su trabajo, también los maltratan y les vulneran sus derechos: "Pues ya a usted sabe que a una persona yo le cargo un viaje y si no me pagan, no le vuelvo a cargar porque como hace uno trabajando gratis como los cilantreros" (Yesid, entrevista, 2018); asimismo, Ana afirma: "Tratándolo a uno mal, hay veces que uno está sentado por ahí y llegan y le tiran a uno piedras y salen" (entrevista, 2018).

\section{Culpabilización y responsabilización de otros}

Otra forma de atribución externa está en el recurso a la culpabilización de otros por su situación, como una forma de ubicar la responsabilidad fuera de sí mismos. Una de las justificaciones más frecuentes en los habitantes es culpar a sus vicios, tal como manifiesta César, quien dice, "Mira, más que todo el destino no, más que todo sabes que [es] la droga. Cuando uno no tiene vicios ni nada, es una ventaja muy grande, pero cuando caes a una olla sin fondo, es mucho más diferente" (entrevista, 2019).

Otros atribuyen la culpa a seres sobrenaturales, como Paola, que ubica en el karma la fuente de su actualidad, "Mi madre sí ejerció este trabajo [sexual], yo con los años me enteré. De pronto, yo digo que esto es un karma, en la familia siempre debe quedar una que siga como esa ley de Dios, no sé" (entrevista, 2018). ${ }^{7}$

Así como también lo hace César:

Mira ya gracias a dios he podido dejar el vicio, pero sin embargo estuve más de 30 años consumiendo, y yo digo que cuando uno más quiere salir el diablo más lo atrae a uno.
Eso como que se adhiere al cuerpo y uno se queda en ese ritmo de vida (entrevista, 2019). ${ }^{8}$

También se halló que los participantes tienden a culpar al destino por su situación, como una forma de fatalismo en la que algunos consideran que su situación es inevitable, pues ya estaba marcada desde antes: "Pues creo que era inevitable llegar aquí, a la vez sí a la vez no, pero ya uno se siente más allegado" (Rosalía, entrevista, 2019). Similar a César quien alude al destino como determinante de su condición actual: "Es muy duro, porque yo antes tenía todas mis comodidades y, por cuestión del destino, lo he perdido todo, mi casa y todo por cuestiones del destino" (entrevista, 2019).

Los habitantes de calle entrevistados afirman que no pueden solucionar sus problemas por sus propios medios. Muchos de estos se tornan dependientes debido a que no buscan otras soluciones aparte de las que puedan ofrecer los demás, por lo que se ve un abandono de su agencia al dejar su futuro en manos de "lo que Dios quiera", configurando una forma de dependencia de otros para la solución de sus impedimentos que se ve fundamentada en las entrevistas realizadas a los habitantes. Tal es el caso de Ana, que afirma que necesita ayuda de su hijo para salir adelante:

Ya mi hijo mayor sí entiende porque él ya sabe, yo le expliqué a él, entonces ya está en el ejército y él me dijo que le iban a dar la tarjeta que le dieron la tarjeta, la pasaba a nombre mío para que yo saque la plata. Esa es la esperanza que tengo de él (entrevista, 2018).

Y Gustavo, quien manifiesta que, sin la ayuda de Dios, no podría cambiar su situación: "Para mí que necesito ayuda de otra persona, ayuda de mí mismo y ayuda de Dios, lo más divino es encontrarme con Dios en cada momento cuando me levanto y cuando me acuesto" (Gustavo, entrevista, 2019).

\section{ATRIBUCIONES DE SÍ Autoconcepto}

Se define como el conjunto de virtudes, cualidades y defectos que el habitante tiene de sí mismo. El autoconcepto puede ser positivo o negativo, el positivo se basa en las fortalezas que la persona ve en sí misma y cómo las utiliza para mejorar los aspectos que no son tan satisfactorios; el negativo está compuesto por todas aquellas percepciones desadaptativas, que llevan al habitante a tener una 
concepción vulnerable de sí mismo (Fariña, García y Vilariño, 2010).

Algunos de los entrevistados dieron cuenta de características propias tales como la edad, el sexo y el nivel educativo como limitaciones para la inclusión laboral. Es así como los participantes afirman que debido a su edad es difícil conseguir trabajo y también estudiar, como se ve manifestado en la entrevista a Paola:

\begin{abstract}
De pronto sí, porque de pronto a la edad que termine para hacer una carrera sí se me va a dificultar para trabajar, ahí tocaría estudiar y conseguir un buen empleo, no más, para hacer una carrera siempre se me dificulta por la edad, porque ahorita la edad es fundamental para trabajar (entrevista, 2018).
\end{abstract}

Se encontró que el autoconcepto negativo está presente, a partir de este nace una percepción de inferioridad debido a su condición, por lo que consideran que no son personas normales y se sienten menos que los demás. Paola, una trabajadora sexual y habitante en calle, afirma: "Cómo me gustaría que me llamaran, no, como una persona normal, por su verdadero nombre, dama de compañía me parece muy bonito, sî" (entrevista, 2018).

Definirse a sí mismo como excluido social es otra descripción recurrente que dan los participantes, ya que mencionan que no tienen contacto con familiares y que sus relaciones personales son las personas en la escala más baja de la estratificación social, como se puede ver en el relato del Rolo:

Uno tiene tres frentes, el familiar, el laboral y el social; si yo me autoexamino a partir de todo lo que he hecho, a nivel familiar estoy obsoleto, lo único que me acompaña es un perro pulgoso; a nivel social, las personas que me acompañan son los vendedores, los ladrones, los policías, el nivel social bajo (entrevista, 2018).

También se halló que el concepto que tienen otras personas sobre ellos, influye en su autoconcepto. La mayoría de las personas describe con características negativas a los habitantes y ellos interiorizan estas descripciones y las empiezan a aceptar como tal, como se manifiesta en la entrevista a Paola: "De puertas para afuera si no saben nada normal, me tratan como una persona normal pero cuando se enteran ya empiezan a mirarlo mal, a hablar mal de uno y uno por ejercer este trabajo ya es una cualquiera (entrevista, 2018). Por otro lado, se encontró que algunos participantes no tienen un concepto claro de ellos mismos, ya que algunos de ellos no se consideran habitantes de calle a pesar de tener todas las características de uno, y otros manifiestan que no se conocen a sí mismos.

\section{Falta de control sobre sí}

No poseer el control de sí mismos parece un elemento común en muchos de los entrevistados, quienes manifestaron que una de las limitaciones para poder salir de su condición es el lograr controlar factores psicológicos como sus emociones, la sensación de ansiedad y la depresión. Por una parte, Gustavo afirma tener dificultades para manejar su ansiedad: "No, el no poder manejar algo es más bien digamos la ansiedad, ya que lo tiene un cuerpo y vamos a uno lo lleva y lo lleva y al final uno se vuelve un perro" (Gustavo, entrevista, 2019). Lo que establece una necesidad de controlar aquellos aspectos propios que algunos consideran emocionales:

Pero de verdad es como solucionar esa parte interior, esa parte emocional, tener más control con mis emociones, porque he sido una persona que lleva todo a los extremos, porque llego y subo y luego vuelvo y me bajo y vuelvo al otro extremo que es todo lo contrario, es como tratar de identificar esas cosas (Jaime, entrevista, 2019).

También entienden como limitación la falta de control en sus motivaciones y acciones, porque muchos de ellos manifiestan que consiguen lo que desean y se sienten bien en un momento, pero después abandonan lo que han conseguido, esto se puede observar en las afirmaciones dadas por dos habitantes de calle:

Yo vuelvo a Bogotá en la segunda semana de
junio y retomo mi trabajo como soldador, pero
debo pagar arriendo, transporte, alimentación
y volver a mi familia y todo eso requiere
dinero, [...] trabajo un tiempo, pero luego
me coge la aburrición y yo le digo 'sabe qué
mija, nos vemos' y me desaparezco. En el
fondo de mi corazón huyo de mí mismo (Rolo,
entrevista, 2018).

Esta falta de control está acentuada por factores externos como el consumo de SPA, que 
los participantes relacionan con la sensación de ansiedad y compulsión:

Pues el principal problema es el consumo de drogas, muchas veces he querido empezar de cero y hacer ese castillo que uno quiere de su vida, pero hay un momento en que no sé, llego hasta cierta parte y se me derrumba todo. Se me despierta como la ansiedad y la compulsión y vuelve y se me cambia la vida totalmente, es estar lleno de sueños e ilusiones y de un momento a otro ya no quiero nada (Jaime, entrevista, 2019).

El caso de Rolo resulta ilustrativo. Él afirma tener la capacidad de satisfacer sus necesidades básicas a partir de ciertas estrategias que ha desarrollado a partir del uso de los recursos y servicios que Ibagué le aporta, "yo vengo a Ibagué, porque es la ciudad más cómoda para el vago" (entrevista, 2019). Sin embargo, afirma que "a lo que más le tengo miedo es a enfermarme, no porque no tenga salud pública, sino porque cuando hay salud y vida lo demás lo puedo conseguir yo solo" (entrevista, 2019), por lo que su mayor miedo radica en el deterioro de sus capacidades de autogestión.

\section{Derelicción}

Este sentimiento nace en los participantes como una respuesta ante la realidad vivida y percibida, comprende el abandono de parte de otros, lo que los lleva a entender que se encuentran solos, que parece incidir en la forma en que se perciben a sí mismos.

\section{Sentimiento de abandono}

La categoría sentimiento de abandono hace referencia al sentimiento que reportan los participantes al no sentir el apoyo de otras personas para mejorar sus condiciones de vida. Por ejemplo, no contar con el apoyo de entidades públicas y privadas, como se ve reflejado en la entrevista a Yesid:

Le dije 'doctora, ya llevo dos años aquí pa'esa vaina y usted no ha salido con nada' y me dijo 'no abuelito, tiene que tener paciencia' y le dije 'sabe qué, deme los papeles para llevarlos a la alcaldía para que publiquen esa vaina. No tengo recursos, no tengo a nadie que me ayude, no tengo familia, no tengo nada, y usted mamándome gallo. Necesito esos papeles pa' yo llevarlos'. Me dijo 'no, no abuelito, esos papeles están conservados, están guardados. ¡Tiene que tener paciencia!' (entrevista, 2018).

También se encontró el sentimiento de abandono respecto de los familiares, que es la categoría con mayor cantidad de citas. Buena parte de los habitantes de calle entrevistados han roto vínculos con su familia y sienten que no pueden contar con ella, sienten que han sido abandonados. Esto se ve evidenciado en el relato de Gustavo:

\section{Imagínate que yo tengo a mi esposa, ella tuvo dos niños y una niña conmigo, entonces en el error, cuando yo me fui a la cárcel fue muy duro para ella. Vivimos diez años y diez años después, es el tiempo que yo ya no la veo y no veo a mis hijos. En este momento quisiera llorar porque es como si estuviera hablando con mi hija, en este momento usted me llena mi corazón, quisiera hablar con alguno de ellos, simplemente hablar (entrevista, 13 de marzo de 2019).}

Es necesario recordar que las decepciones amorosas son una de las causas frecuentes para la llegada a la calle (Alcaldía Ibagué, 2018; MIDESO, 2012). También se presenta el sentimiento de abandono por parte de amigos, ya que sus amigos anteriores, al igual que su familia, rompen vínculos con ellos. Sin embargo, los participantes conocen personas que están en situaciones iguales o similares a las de ellos y hacen amistad, no obstante, estas amistades también son pasajeras debido a que como manifiesta César, pues siempre están esperando algo más: "Amigos no tengo. Yo trato con todo el mundo, pero amigos no, porque las amigas hasta esperando todo el tiempo no que le va a dar y los amigos esperando a que uno les gasté" (César, entrevista, 2019).

\section{Resignación}

La resignación se define como la aceptación de una situación aversiva, tras la cual no se efectúa ninguna acción para acabar con ella. A partir de las entrevistas recogidas se encontró que la resignación en los habitantes de calle es un mecanismo para hacer su situación más llevadera, algunos de los habitantes ligan la resignación a la idea de Dios y se comparan con otros que están en una situación peor para sentirse mejor, como Carlos que afirma:

No creo en el destino, pero sería egoísta conmigo mismo si digo que no hay un Dios, y 
lo que tiene que suceder, sucede. Esta situación era inevitable para mí, yo vine por lana y me quedé trasquilado; lo que tiene que suceder, sucede. Lo que es para uno, es para uno. También considero que está bien resignarse, aceptar la realidad por más dura que sea y sobrellevarla (entrevista, 2019).

También se detectó que algunos habitantes de calle relacionan la resignación al apoyo institucional, en este caso, al hogar de paso, debido a que no ven esta institución como una ayuda pasajera. En su lugar, parece aumentar la dependencia de estas ayudas ya que tienen al alcance la satisfacción de necesidades básicas tales como comer y dormir. Lo que redunda en la aceptación de la situación y la reducción de la búsqueda activa de otras opciones para sobrellevar su situación, tal como se ve reflejado en la entrevista a Jaime, quien piensa:

\begin{abstract}
Más bien buscar soluciones, como el hogar, acá me han acogido y me he alejado de estar por ahí en malas cosas, en la calle encuentras miles de oportunidades, pero más que todo negativas, como yo buscando trabajo y pasan días enteros que no, y estoy pues contento y amañado acá (entrevista, 2019).
\end{abstract}

Esta opinión también se ve reflejada en la entrevista de Rosalía, quien afirma, "Me siento bien, me siento conforme con mi situación actual, no la cambiaría, me siento bien he ido mejorando, gracias al hogar de paso" (entrevista 2019). Sin embargo, esta dependencia contrasta con aquellos que no recurren a instituciones de caridad y asistencia social, tales como Ana, quien desconoce los apoyos y servicios en materia de salud y derechos, por lo que no cuenta con ellos y tampoco los ve necesarios.

\section{DISCUSIÓN}

Una primera consideración para tener en cuenta en la discusión de los resultados es que, aunque inicialmente no se tuvo en cuenta el tiempo de permanencia en calle como un criterio muestral, salvo una participante, todos los demás presentan tiempos de permanencia entre 3 y 45 años en calle. Siguiendo la tipificación presentada por Berho (2006; 2010), que también ha sido tomada por Berroeta y Muñoz (2013), se distingue entre los a) "novatos" o en fase de "desvinculación", como aquellos que, durante su primer año en la calle desarrollan un proceso de desafiliación institucional, relacional y emocional; b) los "experimentados" que entre los 1 y 5 años de permanencia afrontan procesos de vulneración de la integridad personal y el desarrollo de estrategias de supervivencia y c) los denominados "permanentes", quienes parecen tener prácticas de habitanza en torno a la supervivencia, permanencia y resignificación del espacio público, en tanto que llevan más de 5 años en calle.

Los resultados aquí presentados podrían entenderse como respondientes a personas que parecen ostentar cierto grado mayor de permanencia soportado en prácticas establecidas que les han permitido subsistir tanto tiempo. De ahí que sea necesario sugerir la limitación del presente estudio a dicho conjunto de habitantes "permanentes" de las calles, impidiendo la comparación con otros grupos (novatos y experimentados) y generando la necesidad de contrastar los hallazgos y sus posibles variaciones en futuros estudios.

Una segunda consideración está en el diferencial de vulnerabilidad entre sexos. Al respecto, es necesario decir que emitir algún análisis comparativo supera por mucho las intenciones del presente trabajo, sin embargo, una revisión simple de la literatura evidencia cómo las calles implican riesgos para la vida misma, implicando una mayor pluralidad en el caso de las mujeres. Biscotto et al. (2016), afirman que las mujeres presentan mayor fragilidad por su exposición cotidiana a prejuicios, violencias y desigualdades de género, que ponen en riesgo el cumplimiento efectivo de derechos. En adición, la precaria oferta institucional específica para este segmento poblacional coadyuvaría con la invisibilidad de sus necesidades, resultando en un factor de vulnerabilidad (Silva y Passarella, 2015). En adición, Cabrera et al. (2007) establecen que el sexo incide en la presencia en calle, debido a que la mayoría de mujeres cuentan con mayor apoyo familiar e institucional (en casas o refugios de protección a víctimas de violencia intrafamiliar), lo que reduce su llegada permanente a la calle.

$\mathrm{Al}$ recurrir al concepto de marginalidad, la discusión debe centrarse en la limitación de posibilidades para cumplir con las exigencias mínimas del marco normativo y moral de la sociedad generalizada (Cortés, 2012; Germani, 1973; Townsend, 2003), por lo que la disposición para la inacción ante situaciones adversas podría implicar una seria dificultad para esto $y$, por tanto, un factor que facilita la marginación. Es así como cualquier factor que conlleve o facilite la inacción se podría entender 
como un factor de vulnerabilidad ante exigencias externas socioeconómicas tan fuertes como las que comprenden la situación de calle.

Esto coincide, en buena medida, con lo planteado por Kaztman (1999) acerca de la vulnerabilidad, en tanto producto que emerge de la relación entre la precarización de la estructura de posibilidades y la dificultad para movilizar activos o recursos con tal de aprovechar las oportunidades que se presenten. Es de resaltar que factores externos (falta de oportunidades laborales, la oferta institucional, la existencia o no de servicios sociales y de programas de atención especializados enfocados en la población de calle, etc.) se enlazan con factores relacionales (existencia de apoyo familiar, exclusión social en la interacción cotidiana, etc.) y con factores internos o inherentes al individuo (características propias, como la edad o el nivel educativo, las capacidades de regulación emocional, etc.), generando una complejidad en la vulnerabilidad de quienes habitan las calles. Este aspecto amerita mayores reflexiones que sopesen la profundidad real de la propuesta de Kaztman (1999) acerca de la estructura de oportunidades y el modelo AVEO para el caso de la habitanza de calle.

Siguiendo la propuesta de la Depresión por Desesperanza (Abramson et al., 1989; GarcíaAlandete et al., 2009), fue posible evidenciar en las entrevistas y el taller ASM que la evaluación negativa de la situación vivida contempla la escasez en la oferta laboral y de vinculación afectiva y relacional; ya que no hay empleo, no hay familia o esta no quiere saber del habitante de calle, se viven malos tratos y situaciones injustas ajenas al control del individuo. Junto con esto, la percepción de falta de control sobre las propias acciones, motivaciones y emociones parece reforzar la inacción. Es necesario mencionar que una de las recomendaciones de García-Alandete et al. (2009) es justamente la de ampliar la propuesta de la "depresión por desesperanza" incluyendo una dimensión que contemple la evaluación de la incontrolabilidad, lo que es coherente con lo encontrado en el presente trabajo.

Sin embargo, los datos también abundan en emociones ligadas a las percepciones y atribuciones que reportan los participantes, por lo que se hace necesario buscar en otras propuestas teóricas. Por su parte, el concepto de fatalismo abordado por Blanco y Díaz (2007) se entiende como un estado anímico de incertidumbre, inseguridad e indefensión frente a los acontecimientos que están sucediendo. Es la aceptación del destino que les ha tocado, que puede ser dictado por un ser natural, o el Karma.

La falta de control sobre sí mismos está asociada con la dependencia de otros para la solución de sus impedimentos, debido a que considerar que no tienen control, facilita que también consideren que no tienen las capacidades necesarias para solucionar la problemática por sí mismos y promueve la dependencia de los demás para solucionar sus problemas. Esto se ve relacionado con el hecho de que los participantes no se hacen responsables de sus actos y culpan a otros, porque, al depender de otros y no recibir la ayuda necesaria, utilizan la culpa como una justificación para su situación, culpan a otras personas, a sus vicios o al destino. Lo anteriormente mencionado, también se ve inmerso en la teoría del fatalismo, ya que uno de los pensamientos recurrentes de los individuos fatalistas es que las cosas ocurren por capricho del destino, la voluntad de Dios que es inevitable e irremediable. (Blanco y Díaz, 2007).

También es posible encontrar un aporte en la lectura comprensiva de los datos en el sentimiento de derelicción, a partir del cual, quienes están padeciendo una situación aversiva se sienten encerradas en su realidad que parece inmutable. Algunas personas sobrellevan la situación pensando que solo están viviendo una realidad alterna, que en algún momento acabará, lo que podría entenderse como una forma de abandono de sí mismo, una manera de huir, tal como lo propuso Rolo. Para Martuccelli (2007), la derelicción sería el reflejo subjetivo de la evaluación existencial a la que asisten los actores a manera de contraste de sus propias vidas respecto de un ideal de "la verdadera vida" bajo la premisa de vivir todas las experiencias, potenciar los talentos y hacerlo sin límites. Es claro que la vida en el margen está demarcada como una vida con posibilidades limitadas, por lo que se pensaría que se genera un sentimiento de derelicción o de abandono, abandono de sí, esto es, impotencia, incapacidad, fracaso, sometimiento, encierro, reclusión, desesperanza, destierro de la realidad y por tanto depreciación de la propia existencia.

Martuccelli y Santiago (2017) también proponen la derelicción como forma de entender por qué las poblaciones vulneradas no se consideran tal, en tanto sienten que admitirlo sería aceptar el encierro en dicha condición, quizá dictada por el destino, por ello, el apoyo que otros les brindan es 
reducido y solo se da en tanto la persona demuestra ser un marginado social. Esto se ve reflejado en que algunos no se reconozcan a sí mismos como habitantes de calle, a pesar de no tener un lugar para dormir, no tener un trabajo estable y haber roto lazos con sus familiares, principalmente debido a la mala reputación que acarrea la habitanza de calle y el estigma que acarrearía. Asimismo, se evidencia el entrelazamiento de su autoconcepto, que es afectado por la opinión ajena, con la inconsistencia posicional, ya que al ser tildados algunos habitantes de calle como "locos" o como "personas que no valen la pena para formar una familia o tener una relación" por su condición, su autoconcepto se ve afectado de forma negativa, haciendo que estos se sientan inferiores y se automarginan; respecto del concepto negativo que tienen los demás sobre ellos, se asocia con el sentimiento de abandono, que se puede ver de forma más específica en el sentimiento de abandono por parte de familiares. Abandonados por los otros cercanos, por los otros institucionales e incluso abandonados por ellos mismos a la deriva, los individuos sienten haber sido expulsados de lo real, privados de participación y vulnerables a cualquier "cambio de aire" (Martuccelli y Santiago, 2017), lo que refuerza su dificultad de pensar un futuro para sí mismos.

Los factores de vulnerabilidad cognitiva mencionados parecen implicar una dinámica circular en que los individuos consideran que las condiciones adversas en que viven no solo son naturales, sino que son merecidas e incluso destinadas a ellos (ver Figura 1). Se caracteriza por la inacción en la búsqueda de cambio, por la reacción antisocial que, valida el estereotipo (similar a la expuesta por Elías y Scotson, 2016), el temor al encierro en su situación, la dependencia frente a otros y un correspondiente sentimiento de abandono, por lo que las personas que llegan a esto suelen evitar la interacción con otros y prefieren la automarginación.

\section{CONCLUSIONES}

Los elementos relacionados con los resultados, así como el autoconcepto, la resignación, sentimiento de abandono, la culpabilización a otros, la falta de control sobre sí, la dependencia de otras personas y las limitaciones relacionadas con conseguir trabajo son algunos de los motivos por los que los habitantes de calle permanecen en su condición. Estos factores parecen tener relación entre sí, muchos de ellos apoyan o facilitan otros. Así, no poseer el control sobre sus acciones y emociones se torna en una limitación para poder conseguir y mantener un empleo; por consiguiente, habría que estudiar de manera detenida las relaciones que se establecen entre estos con tal de clarificar las posibles relaciones causales y multidireccionales que componen la vulnerabilidad cognitiva de la situación de calle.

La desesperanza agrupa factores como la evaluación negativa de la situación vivida, la derivación de efectos adversos y la atribución de características negativas sobre sí mismo (García-Alandete et al., 2009), e incluiría la falta de control de emociones y conductas, que, siguiendo lo manifestado por los participantes, aumenta las posibilidades de inacción.

Por su parte, en el componente motivacional y emocional resalta el sentimiento de derelicción y el fatalismo. El primero implica la sensación de encierro social junto con el abandono, incluso el abandono de sí a la suerte o al destino mismo; el otro corresponde con asumir la situación actual en tanto se entiende que podría empeorar. Ambos, derelicción y fatalismo parecen apuntar a la resignación como forma de tener una vida más llevadera, sin embargo, los participantes reconocen necesitar y pedir ayuda de otras personas e instituciones. Esta les es negada por su condición de marginalidad, lo que refuerza el sentirse abandonados por algunos o todos.

Frente al temor de empeorar la actual situación como modulador de la acción, vale la pena plantear la similitud que esto guarda con el concepto de inconsistencia posicional, en el que se guarda temor debido a la percepción de vulnerabilidad ante el cambio, por lo que se reconoce una falta de herramientas y recursos con los que afrontar cualquier dificultad, inconveniente o desafío social, que se caracteriza por el temor permanente a perder la posición social y económica ocupada, por lo que se acompaña por sufrimiento y ansiedad (Araujo y Martuccelli, 2011).

Ante esto, y reconociendo las limitaciones del presente estudio y su alcance descriptivo, se propone evaluar de forma precisa la presencia y el grado de la desesperanza aprendida en esta población, a partir de mediciones extensas que permitan establecer correlaciones entre los factores mencionados. También se plantea la necesidad de trabajar con las instituciones de servicio, tales como los albergues y hogares de paso, con tal de reducir el impacto de su oferta en la dependencia y resignación de sus usuarios. Se sugiere para posibles métodos 
de intervención trabajar en los factores aprendidos empezando por el autoconcepto que presentan los habitantes y continuando por la resignación, así si logran ver una imagen más positiva de su realidad y de ellos mismos, se puede seguir fortaleciendo los otros aspectos; también se considera de importancia que se trabaje en los lazos familiares o amistosos que conserven los participantes, ya que es la categoría con más datos recogidos, es decir, la mayoría de los habitantes tienen redes sociales de apoyo muy carentes; así también se disminuirá el sentimiento de abandono y la culpa a otros por su situación.
Para finalizar y retomando el sentimiento de abandono, algunos habitantes consideran que su situación es una problemática individual, sin embargo la habitanza de calle es problema social al que no se le ha dado la importancia requerida, por tanto se espera que esta investigación sirva como apoyo para próximas investigaciones, programas e intervenciones en donde las entidades públicas y privadas muestren interés en ayudar a solventar la problemática, poniendo como fin principal la dignidad humana. 


\section{REFERENCIAS}

Abramson, L. Y., Metalsky, G. I. y Alloy, L. B. (1989). Hopelessness depression: A theory-based subtype of depression. Psychological Review, 96, 358-372. https://doi.org/10.1037/0033-295X.96.2.358

Alcaldía Municipal de Ibagué [Alcaldía Ibagué]. (2018). Censo y caracterización de habitantes de la calle Ibagué-2016. Fundación Aguapanelos de la Calle. Convenio 1689 del 13 de octubre. Ibagué.

Andreu, J. A. (2002). Las técnicas de Análisis de Contenido: una revisión actualizada. Fundación Centro de Estudios Andaluces. Universidad de Granada.

Araujo, K. y Martuccelli, D. (2011). La inconsistencia posicional: un nuevo concepto sobre la estratificación social. Revista CEPAL, 103, 165-178. https://repositorio.cepal.org/bitstream/ handle/11362/11453/103165178_es.pdf

Arias, A. y Pamplona, J. (2015). Razones de hombres jóvenes habitantes de calle, entre los 20 y 50 años, para continuar viviendo en la calle [Trabajo de grado]. (L. Castillo Dir.). Programa de psicología, Universidad de Antioquia. http://200.24.17.74:8080/ jspui/bitstream/fcsh/295/1/AriasAna_razoneshombresjoveneshabitantescalle2050anoscontinuarviviendocalle.pdf

Bachiller, S. (2010). El aislamiento social como supuesto articulador de las teorías sobre la exclusión y el sinhogarismo: críticas y aportes etnográficos. Revista Cutura - Hombre - Sociedad, 19, 9-21. https://doi.org/10.7770/cuhso.v19i1.305

Bayón, M. C. (2016). Accumulating Disadvantages, Multiplying Inequalities: Biographies of Poverty in Mexico City. Journal of Poverty. https://doi.org/10.1080/10875549.2016.1141385

Beck, A. y Weissman, A. (1974). The measurement of pessimism: the hopelessness scale. Journal of Consulting and Clinical Psychology, 42 (6), 861-865. 10.1037/h0037562

Berho, M. (2006). Identidad marginal entre personas sin hogar de la ciudad de Temuco, Chile. Revista Cultura - Hombre Sociedad, 11(1), 39-55. https://doi.org/10.7770/cuhso.v11i1.243

Berho, M. (2010). Dos relatos, un análisis y un excurso sobre las identidades y la relación con la ciudad entre los "moradores de la calle" en Temuco, Chile. Revista Cultura - Hombre - Sociedad, 19, 23-36. https://doi.org/10.7770/cuhso.v19i1.306

Berroeta, H. y Muñoz, M. I. (2013). Usos y significados del espacio público en personas en situación de calle. Un estudio en Valparaíso y Viña del Mar. Revista de Psicología, Universidad de Chile, 22(2), 3-17. DOI: 10.5354/0719-0581.2014.30849

Biscotto, P.R., Jesus, M.C.P., Silva, M.H., Oliveira, D.M. y Merighi, M.A.B. (2016). Understanding of the life experience of homeless women. Rev Enferm USP, 50(5), 749-755. https:// doi.org/10.1590/S0080-623420160000600006

Blanco, A. y Díaz, D. (2007). El rostro bifronte del fatalismo: fatalismo colectivista y fatalismo individualista. Psicothema, 19(4), 552-558. http://www.psicothema.com/psicothema.asp?id=3396

Cabrera, P.J., Rubio, M. y Fernández, E. (2007). Las personas sin hogar en la Comunidad de Madrid. Universitas. Revista de Filosofía, Derecho y Política, 6, 107-126. https://dialnet.unirioja. es/servlet/articulo?codigo $=2390122$

CEPAL. (2010). Indicadores de pobreza y pobreza extrema utilizadas para el monitoreo de los ODM en América Latina. https://www.cepal.org/sites/default/files/static/files/ indicadores_de_pobreza_y_pobreza_extrema_utilizadas_para_ el_monitoreo_de_los_odm_en_america_latina.pdf

Correa, M. (2007). Para una nueva comprensión de las características y la atención social a los habitantes de calle. Eleuthera, 1 , 91-102. http://eleuthera.ucaldas.edu.co/downloads/Revista1_6.pdf

Cortés, A. (2012). Modernización, dependencia y marginalidad: itinerario conceptual de la sociología latinoamericana. Sociologias, 14(29), 214-238. https://www.scielo.br/pdf/soc/ v14n29/a09v1429.pdf

Cottet, P. (2014). Tres versiones para el diseño de investigaciones sociales. En M. Canales (ed.), Investigación Social. Lenguajes del diseño. LOM ediciones.

Cunda, M. y Silva, R. (2020). Me chamam rua, população, uma situação: os nomes da rua e as políticas da cidade. Psicologia \& Sociedade, 32, 1-17. http://dx.doi.org/10.1590/1807-0310/ 2020v32223876

Del Monte Madrigal, J. (2018). El vórtice de precarización. El proceso de indigencia en una ciudad fronteriza del norte de México (tesis de doctorado). Centro de Estudios Sociológicos. Doctorado en Ciencia Social con especialidad en Sociología. El colegio de México. https://ces.colmex.mx/pdfs/tesis/tesis_delmonte_madrigal.pdf

Díaz-Bravo, L., Torruco-García, U., Martínez-Hernández, M. y Varela-Ruiz, M. (2013). La entrevista, recurso flexible y dinámico. Investigación en Educación Médica, 2(7), 162-167. http://www.scielo.org.mx/scielo.php?script=sci_arttext\&pi$\mathrm{d}=$ S2007-50572013000300009\&lng=es\&tlng=es

Elías, N. y Scotson, J. L. (2016). Establecidos y Marginados. Una investigación sociológica sobre problemas comunitarios. Fondo de Cultura Económica.

Evans, R. y Forsyth, C. (2004). Risk Factors, Endurance of Victimization, and Survival Strategies: The Impact of the Structural Location of Men and Women on Their Experiences Within Homeless Milieus. Sociological Spectrum, 24(4), 479505. https://doi.org/10.1080/02732170390260413

Fariña, F., García, P. y Vilariño, M. (2010). Autoconcepto y procesos de atribución: estudio de los efectos de protección/ riesgo frente al comportamiento antisocial y delictivo, en la reincidencia delictiva y en el tramo de responsabilidad penal de los menores. Revista de Investigación en Educación, 7, 113-121.

García-Alandete, J., Gallego-Pérez, J.F. y Pérez-Delgado, E. (2009). Sentido de la vida y desesperanza: un estudio empírico. Universitas Psychologica, 8(2), 447-454. https://www.redalyc. org/pdf/647/64712165013.pdf

Germani, G. (1973). El concepto de marginalidad. Significado, raíces históricas y cuestiones teóricas, con particular referencia a la marginalidad urbana. Ediciones Nueva Visión.

Gibbs, G. (2012). El análisis de datos cualitativos en investigación cualitativa. Ediciones Morata.

Gómez, C. (2015). El habitante de calle en Colombia: Presentación desde una perspectiva social-preventiva. Actualidad Jurídica, 8. https://www.uninorte.edu.co/documents/4368250/0/El+hab itante+de+la+calle+en+Colombia+Presentaci\%C3\%B3n+desde+una+perspectiva+social-preventiva/98003d14-5fee-437b$8063-\mathrm{c} 13 \mathrm{~b} 4 \mathrm{f} 7 \mathrm{fc} 676$ ? version $=1.0$ 
González, J. y Hernández, A. (2012). La desesperanza aprendida y sus predictores en jóvenes: análisis desde el modelo de Beck. Enseñanza e Investigación en Psicología, 17(2), 313-327. http:// www.redalyc.org/articulo.oa?id=29224159015

Hernández, R. y Mendoza, P. (2018). Metodología de la investigación. Las rutas cuantitativa, cualitativa y mixta. McGraw-Hill Interamericana.

Kaztman, R. (1999). Marco conceptual sobre activos, vulnerabilidad y estructura de Oportunidades. En Activos y estructuras de oportunidades estudios sobre las raíces de la vulnerabilidad social en Uruguay, (pp. 7-36). Comisión Económica para América Latina y el Caribe, CEPAL. https://www.cepal.org/ es/publicaciones/28663-marco-conceptual-activos-vulnerabilidad-estructuras-oportunidades

Ley 1641 de 2013. Por la cual se establecen los lineamientos para la formulación de la política pública social para habitantes de la calle y se dictan otras disposiciones. Congreso de la República de Colombia. http://wsp.presidencia.gov.co/Normativa/Leyes/ Documents/2013/LEY\%201641\%20DEL\%2012\%20DE\%20 JULIO\%20DE\%202013.pdf

Makowski, S. (2010). Jóvenes que viven en la calle. Siglo XXI.

Martínez, M. (2006). Ciencia y arte en la metodología cualitativa. Editorial Trillas.

Martinic, S. (1992). Investigación para la acción estrategias de capacitación. Análisis estructural: Presentación de un método para el estudio de lógicas culturales. Centro de Investigación y Desarrollo de la Educación (CIDE). https://repositorio.uahurtado. cl/bitstream/handle/11242/8291/6528.pdf

Martuccelli, D. (2007). Cambio de rumbo. La sociedad a escala del individuo. LOM ediciones.

Martuccelli, D. y Santiago, J. (2017). El desafío sociológico hoy. Individuo y retos sociales. Centro de Investigaciones Sociológicas (CIS). CYAN.

Meert, H., Maurel, E., Wolf, J., Nicholas, S., Maas, R., KochNielsen, I., Christensen, I., y Cabrera, P. (2003). The changing profiles of homeless people macro social context and recent trends. FEANTSA. https://www.feantsaresearch.org/download/2004_homelessness_in_the_written_press4562555879183715479.pdf

Meyer, S. (2015). Examining women's agency in managing intimate partner violence and the related risk of homelessness: The role of harm minimisation. Global Public Health: An International Journal for Research, Policy and Practice, 11(1-2), 198-210. https10.1080/17441692.2015.1047390

Ministerio de Desarrollo Social y familia [MIDESO]. (2012). En Chile Todos Contamos. Segundo catastro nacional de personas en situación de calle. Noche digna. Chile. http://www.nochedigna.cl/ wp-content/uploads/2017/03/En_Chile_Todos_Contamos_baja.pdf

Ministerio Salud. (2018). Política pública social para habitante de calle-PPSHC-. Oficina de promoción social. Grupo de gestión integral en promoción social. https://www.minsalud. gov.co/sites/rid/Lists/BibliotecaDigital/RIDE/DE/PS/politica-publica-social-habitante-de-calle.pdf

Moreno, M. P. (2001). Psicología de la marginación social: conceptos, ámbitos y actuaciones. Ediciones Aljibe.

Nieto, C. y Koller, S. (2015). Definiciones de Habitante de Calle y de Niño, Niña y Adolescente en Situación de Calle: Diferencias y Yuxtaposiciones. Acta de Investigación Psicológica, 5(3), 21622181. https://www.redalyc.org/articulo.oa?id=358943649005
Nino, M., Loya, M. y Cuevas, M. (2009). Who are the Chronically Homeless? Social Characteristics and Risk Factors Associated with Chronic Homelessness. Journal of Social Distress and the Homeless, 191(1-2), 41-65. https://doi. org/10.1179/105307809805365145

Ortiz, F. (2007). La entrevista de investigación en las ciencias sociales. Limusa Noriega Editores.

Patrício A. C. F. A., Silva R. A. R., Araújo R. F., Silva R. F., Nascimento G. T. S., Rodrigues T-T. D. B. y Leite, M. A. P. (2019). Common mental disorders and resilience in homeless persons. Revista Brasileira de Enfermagem, 72(6), 1526-1533. http://dx.doi.org/10.1590/0034-7167-2018-0541

Quintero, L. (2008). La exclusión social de "habitantes de la calle" en Bogotá: una mirada desde la bioética. Revista Colombiana de Bioética, 3(1), 101-144. Universidad del Bosque. http:// www.bioeticaunbosque.edu.co/publicaciones/Revista/Revista5/ Articulo4.pdf

Rapley, T. (2014). Los análisis de la conversación, del discurso y de documentos en investigación cualitativa. Ediciones Morata.

Sentencia C-385 de 2014. Por la cual se establecen los lineamientos para la formulación de la política pública social para habitantes de la calle y se dictan otras disposiciones. Corte Constitucional de Colombia. http://www.corteconstitucional. gov.co/relatoria/2014/c-385-14.htm

Sentencia T-881, 2002. Principio de dignidad humana. Corte suprema de justicia, sala de casación penal. República de Colombia. http://www.corteconstitucional.gov.co/relatoria/2002/t-881-02.htm

Silva, R. A y Passarrella, B. A. C. (2015). Violence in the lives of homeless women in the city of São Paulo, Brazil. Interface (Botucatu), 19(53), 275-85. https://doi.org/10.1590/1807-57622014.0221

Soliz, F. y Maldonado, A. (2006). Guía de metodologías comunitarias participativas. http://www.clinicambiental.org/docs/ publicaciones/guia5.pdf.

Soria, M.; Otamendi, A.; Berrocal, C.; Caño, A. y Rodríguez Naranjo, C. (2004). Las atribuciones de incontrolabilidad en el origen de las expectativas de desesperanza en adolescentes. Psicothema, 16(3), 476-48. https://www.redalyc.org/ pdf/727/72716322.pdf

Souza, M. R. R., Oliveira, J. F., Chagas, M. C. G. y Carvalho, E. S. S. (2016). Gender, violence and being homeless: the experience of women and high risk drug use. Rev Gaúcha Enferm, 37(3), e59876. http://dx.doi.org/10.1590/1983-1447.2016.03.59876

Suárez-García, C. J. (2017). Estigma, communitas y modos de corrección para los habitantes de la calle en Bogotá (2000-2010). Sociedad y Economía, 32, 195-216. http://www.scielo.org.co/ pdf/soec/n32/1657-6357-soec-32-00195.pdf

Townsend, P. (2003). La conceptualización de la pobreza. Comerio Exterior, 53(5), 445-452. http://revistas.bancomext. gob.mx/rce/magazines/20/6/RCE6.pdf

Universidad Nacional de Colombia y Ministerio de la Protección Social [UNAL y MinProtección]. (2007). Identificación, documentación y socialización de experiencias de trabajo con habitantes de y en calle. República de Colombia. https:// docplayer.es/16961943-Identificacion-documentacion-y-socializacion-de-experiencias-de-trabajo-con-habitantes-de-y-en-calle.html 


\section{NOTAS}

1 Según la sentencia T-881 de 2002 de la Corte Suprema de justicia colombiana, la dignidad se entiende como derecho fundamental que equivale a "(i) al merecimiento de un trato especial que tiene toda persona por el hecho de ser tal; y (ii) a la facultad que tiene toda persona de exigir de los demás un trato acorde con su condición humana". Al ser decretado como un derecho fundamental se debe velar porque cada persona tenga una vida digna, pero en el mundo moderno es un derecho del que no todos pueden gozar.

2 A propósito, es posible evidenciar un adelanto relevante al respecto en la línea del "sinhogarismo", vigente en la literatura especializada y que ha cobrado relevancia en países centrales a partir de la conformación de la ETHOS (European Typology on Homelessness) y los informes de instituciones internacionales multilaterales acerca de desigualdad expresada en el acceso a un techo. Se entiende que lo que prima en la definición de la situación de calle es la falta de vivienda en condiciones dignas (Nieto y Koller, 2015; Cabrera, Rubio y Fernández, 2007)

3 Habría que estudiar, en complemento, las restricciones a nivel de la estructura de oportunidades, en especial si se entiende el carácter multidimensional y complejo que permite la diversificación de configuraciones en las que se puede tener trabajo, acceso a servicios de salud, vinculación familiar y vivienda y aun así ser un habitante de calle. Es por lo que, siguiendo la crítica presentada por Kaztman (1999), resulta pertinente descentrar la mirada en los actores y plantear una revisión de la oferta de posibilidades laborales, educativas y de interacción social, entre otras, necesarias para sostener la vida en sociedad según el marco moral, como oportunidades para movilizar activos y articular proyectos de vida.

4 A propósito, Kaztman (1999) afirma que "La falta de acceso a oportunidades, a recursos o servicios en el momento oportuno, las decisiones inadecuadas y las pérdidas de recursos de diverso tipo que se generan por fracasos en el intento de resolver los problemas, en la medida en que se van acumulando, generan una cadena de frustraciones que minan principalmente la autoestima y la voluntad de superación. En muchos casos, esta cadena parte desde la familia de origen, sin que se logre revertir en forma sustantiva este proceso" (pp. 153-154).

5 Parque ubicado cerca al centro histórico, económico y administrativo de la ciudad de Ibagué y cercano al terminal de transportes, es reconocido como uno de los puntos clave de concentración y tránsito de habitantes de y en calle.

6 Institución administrada por la Pastoral Social que brinda servicios de atención a necesidades básicas tales como pernoctar, seguridad, aseo y alimentación. Al momento del trabajo de campo en el 2018-2019, la institución contaba con financiación parcial de la administración municipal, así como era centro para varios programas de atención psicosocial para habitantes de y en calle, siendo la institución más grande con este fin del municipio de Ibagué.

7 Énfasis agregado por la autora.

8 Énfasis agregado por la autora. 